\title{
PRACTICE
}

\section{Six Decades of the National Science Foundation's Commitment to Undergraduate Research}

Susan Rundell Singer, Rollins College

\begin{abstract}
For 60 years, the National Science Foundation's commitment to undergraduate research experiences has shaped the course of undergraduate research opportunities, from apprenticeship model-based experiences to team-based and classroom-based collaborations for a diverse group of students. Scaling the opportunity so that students may participate in an equitable and inclusive way has been a priority since the inception of the program. Applying the growing research base in undergraduate science, engineering, and mathematics education to development of optimal research experiences for undergraduates is the next frontier.
\end{abstract}

Keywords: course-based research, history, National Science Foundation, undergraduate research

doi: $10.18833 /$ spur/3/2/7

Undergraduate research made the headlines of Nature in November 1958, as the US National Science Foundation (NSF) launched funding for undergraduate research on an experimental basis ("National Science Foundation Grants for Undergraduate Research" 1958, 1346). Approximately 1,000 undergraduates in biology, engineering, mathematics, and physics across 100 institutions were funded for up to 400 hours during that first summer or academic year. Six decades later, about 8,500 students benefit each year, either working individually through a supplement to an NSF investigator (about 3,500 students) or at one of approximately 500 Research Experiences for Undergraduate sites, hosting 5,000 or so undergraduate researchers. Excepting a hiatus in funding in the early 1980s, undergraduate research has continued as a vibrant program across research directorates and was the subject of a National Academies of Sciences, Engineering, and Medicine (NASEM) consensus study released in 2017 (NASEM 2017). Over time, undergraduate research experiences have broadened to include community college students and have expanded into the classroom and teaching laboratory to scale the benefits of the traditional apprenticeship model. Although other funders have and continue to spread the benefit of a research experience, the consistent and intentional focus of the NSF has shaped the trajectory of these opportunities. This article explores the influence of the NSF on the current status of undergraduate research experiences.

The launch of Sputnik brought laser-focused attention to and investment in science education in the late 1950s. Undergraduate research was not a new concept, although substantive programmatic investment was. Looking back 200 years, Wilhelm von Humboldt's ideal university brought professor and student together in collaborative research (Zupanc 2012). This German university model first made its way to the United States in the more practically focused institutions. One of the earliest examples was Rensselaer Polytechnic Institute, the oldest engineering school in the country, founded in 1824. Stephen van Rensselaer and Amos Eaton had distinctive approaches to pedagogy - "During the day no lectures will be given by the professors, but under their superintendence the students, divided into sections, will perform all the experiments and give the explanations, the students thus acting as lecturers and the professors as auditors" (Ricketts 1934, 31). By 1927, the class of 1902 had established a graduation prize for a fourth-year student in the School of 
Science or School of Engineering with at least two semesters of undergraduate research and the strongest research results presented as a thesis, report, or submitted paper (RPI 2019). At liberal arts universities, the shift came later. In 1847, Benjamin Silliman set up the first chemistry lab at Yale, funding the equipment and paying for rent (Whitman 1898, 201). By the 1880s, Johns Hopkins had established itself as a major research institution engaging students in research laboratories. In the early 1900s, Thomas Hunt Morgan's undergraduates at Columbia, including Calvin Bridges and Alfred Sturtevant, were making groundbreaking genetics discoveries that persist in today's textbooks. With this long history, it is not surprising that the intrinsic value of undergraduate research participation was a deeply held and unquestioned belief and became a priority at the NSF in 1958.

The context in which NSF launched undergraduate research funding set the trajectory for decades of discussion about quality, merit, equity, and inclusion, as well as the role of education expertise in the research agency (England 1982). Throughout the 1950s, Harry Kelly provided leadership for the Science Personnel and Education Division, guiding NSF as it established its role in the education sphere, initially through the support of competitive graduate fellowships. In the mid-1950s, the predoctoral fellowship program was critiqued for being elitist, an argument linked to the ability of the recipients to select their graduate schools, assuming acceptance. Most of these talented students attended a relatively small number of elite graduate schools. The element of choice persists in today's NSF Graduate Research Fellowship Program.

Attention turned to precollege and undergraduate populations as a way to more broadly increase the talent pool in science. Improving teacher quality was a scalable approach to providing more youth with high-quality science learning. In 1957, funding for summer institutes for high school and college teachers grew from 7 percent to 25 percent of the total NSF budget in a single budget year (England 1982, 244). Equity conversations revolved around which institutions to fund in the South, where racial segregation persisted. In 1955, Harry Kelly sent a formal letter to all institute directors stating "the Foundation's 'understanding' that no one would be barred from participating or unfavorably discriminated against because of race, color, or religion" (England 1982, 245).

For undergraduates, scholarships were discussed in the 1950 s as a way to address shortages of expertise in science-related fields, but scholarships did not gain traction. Thirty years later, in response to the American Competitiveness and Workforce Improvement Act of 1998 (Pub. L. No. 105-277), NSF created the Computer Science, Engineering, and Mathematics Scholarship (CSEMS) program. The current Scholarships for STEM (S-STEM) program emerged from the CSEMS program and the H-1B Visa Reform Act of 2004 (Pub. L. No. 108-447) that directed 30 percent of H-1B visa income to NSF for scholarships and other undergraduate activities. The S-STEM scholarship program continues today, supporting low-income students with programming that often includes research or internship experiences for participants. In 2002, the Robert Noyce Teacher Scholarship Program was initiated to prepare teachers for high-needs schools, thus linking the $\mathrm{K}-12$ and precollege efforts to increase the talent pool.

What did stick in the 1950s was undergraduate research. The small liberal arts colleges viewed themselves as research institutions, relying heavily on undergraduate research collaborators and successfully obtaining NSF research funding (England 1982, 260). In advance of the 1957 undergraduate research program, awards to specifically support undergraduate research were made in 1955, to Reed College and Harvard, and in 1956, to Carleton College and Johns Hopkins (England 1982, 264). Where to situate undergraduate research funding has always been a sensitive topic. Early on, a program officer in the Biological and Medical Sciences Division expressed bitterness in an annual report about the shift in undergraduate research funding to the Science Personnel and Education Division. Today, undergraduate research is categorized as research and coordinated by the Division of Undergraduate Education, with funding situated and funding decisions made within each directorate, including research in education in the Education and Human Resources Directorate.

Undergraduate research funding continued uninterrupted for over two decades, until President Reagan took office in January 1981. In FY 1981, the Science and Engineering Education (SEE) portion of the NSF budget ( $\$ 34.5$ million) experienced $\$ 16$ million in rescissions (NSF Budget FY 1982, Revised Budget 1981). The FY 1982 SEE budget was slashed from $\$ 111.9$ million to $\$ 9.9$ million, retaining only funding for graduate fellowship awardees entering their second and third years. The justification offered for reducing SEE activities by $\$ 102$ million was expressed as follows:

Insuring U.S. scientific strength through research in the major fields of science and engineering is an overriding priority in FY 1982. The existing economic crisis dictates that only the most critical science support activities be funded and, in particular, only those that are perceived as most likely to contribute to scientific advancement and economic progress. In these circumstances, NSF science education activities are discontinued in FY 1982. (NSF Budget FY 1982, Revised Budget 1981)

The resurgence of funding for undergraduate education was heavily influenced by two reports emerging from the convening of presidents of 48 of the top 50 liberal arts colleges at Oberlin in June of 1985 and 1986 (Carrier 
and Davis-Van Atta 1987; Maeroff 1985). These research colleges disproportionately contributed to the production of students who later pursued PhDs. Their success correlated with the integration of research and education, including undergraduate research. The college presidents called out the challenges of obtaining laboratory equipment to ensure ongoing success. The Council on Undergraduate Research (CUR), founded in 1978 by chemists, epitomized the commitment of these research colleges to integrating education and research. In FY 1985, the NSF launched the College Science Instrumentation Program, with a 50 percent increase in the budget in FY 1987 (\$7.5 million). The target audience was liberal arts colleges. In FY 1988, the program was renamed Instrumentation and Laboratory Improvement (ILI) and eligibility was extended to two-year and doctoral degree-granting institutions. Simultaneously, support returned for faculty and curriculum development through the Undergraduate Faculty Enhancement (UFE) and Course and Curriculum Development (CCD) programs. The three programs merged in 1999 and have continued to morph to integrate the multiple dimensions of supporting undergraduate learning and research on learning.

In 1987, after a five-year hiatus, undergraduate research funding returned in the Research Experiences for Undergraduates (REU) program, offering both site project funding and supplements to NSF research grants. Note that across all of NSF it is possible to include undergraduate researchers in a proposal without going through the supplement process. That same year, the National Conference on Undergraduate Research (NCUR) was launched. The REU program was fully funded through the research directorates at NSF, with the investment more than doubling from \$9 million in 1988 to $\$ 20.7$ million in 1990 . In FY 2018 (NSF FY 2019 Budget Request to Congress), the combined investment in REU site and supplement awards was $\$ 87.49$ million, with a 12.7-percent decrease from that amount in the request for FY 2020 (NSF FY 2020 Budget Request to Congress). Undergraduate research is now supported by a robust infrastructure developed, in part, with NSF support. CUR expanded its support to all undergraduate institutions and merged with NCUR in 2010. The Community College Undergraduate Research Initiative and CUR have developed resources with NSF funding that have been supporting community college undergraduate research for over a decade. Undergraduate research is deeply embedded in the culture of doctoral degreegranting institutions, with REU sites attracting students across institutions to immerse themselves in a summer of research and explore research careers and graduate study.

Although progress with undergraduate research opportunities has been inspiring, the challenges of equity, inclusion, and reach that NSF staff grappled with in the 1950s continue. NSF-funded ethnographic research of Laursen and colleagues $(2010,203-7)$ on undergraduate research at four liberal arts colleges revealed the centrality of authenticity of the research problem and the lack of sufficient mentoring for undergraduate research mentors. The study identified the need to broaden inclusion in these experiences and argued for early research experiences and the potential for integrating research experiences into the classroom as a way to scale the advantages of a research experience (Laursen et al. 2010, 213-19).

NSF investments in course-based research began growing in the mid-2000s, especially in genetics and other areas of life sciences (Wei and Woodin 2011). Work focused on both individual courses and multi-institutional collaborations, as illustrated by the following examples. Malcolm Campbell launched the Genome Consortium for Active Learning to engage undergraduates at small colleges in genomic research through the use of shared instrumentation funded by NSF (Campbell et al. 2007). Another group of liberal arts colleges used iterative faculty development to support faculty in integrating genomics approaches into their own research and bringing that to the classroom (Banta et al. 2012). About 100 years after undergraduates in Morgan's Drosophila lab published groundbreaking genetics findings, 940 undergraduates from multiple colleges and universities published their collective genomics research on the evolution of the Drosophila Muller F element (Leung et al. 2015). Focusing on early research experiences, the Howard Hughes Medical Institute-supported Science Education Alliance Phage Hunters Advancing Genomics and Evolutionary Science (SEA-PHAGES) program further scaled authentic research to introductory biology students with NSF support (Jordan et al. 2014; Staub et al. 2016).

The focus on inclusion and broadening participation through authentic research experiences early in the undergraduate years, including course-based research experiences, arose as a priority in the President's Council of Advisors on Science and Technology (PCAST) policy report, Engage to Excel: Producing One Million Additional College Graduates with Degrees in Science, Technology, Engineering, and Mathematics (2012). A key recommendation in the Engage to Excel report was to "advocate and support replacing standard laboratory courses with discovery-based research courses." One year later, the National Science and Technology Council's Committee on STEM Education released the first Federal Science, Technology, Engineering, and Mathematics (STEM) Education: 5-Year Strategic Plan (2013), with four undergraduate strategic goals, including "federally supported entities, to provide relevant and authentic STEM learning and research experiences for undergraduate learners, particularly in their first two years." Implementation of the five-year strategic plan occurred through a focused Cross-Agency Priority Goal process, which included development of metrics and 
quarterly reporting on Performance.gov, a US government website. NSF provided leadership for the undergraduate objectives. A common focus for many federal agencies is preparing the next generation of STEM workers through research experiences. Together, the agencies created a common portal-STEMUndergrads.science.gov - to provide a single point of access to information on federally funded opportunities to engage in research for learners and their mentors across the nation.

As part of the cross-agency work, NSF commissioned the NASEM Board on Science Education to evaluate the current knowledge base on the broad array of undergraduate research experiences, including course-based research; to define "authentic research"; to assess the evidence of benefits to participants; to identify gaps in the research; and to develop a robust framework for further investigations (NASEM 2017, 20). The NASEM report recognized the heterogeneity of undergraduate research experiences and the limitations of the binary distinction between authentic and inauthentic, electing to offer instead a set of characteristics of the undergraduate research experience, as follows (NASEM 2017, 34):

- It engages students in research practices, including the ability to argue from evidence.

- It aims to generate novel information with an emphasis on discovery and innovation or to determine if recent preliminary results can be replicated.

- It focuses on significant, relevant problems of interest to STEM researchers and in some cases a broader community (e.g., civic engagement).

- It emphasizes and expects collaboration and teamwork.

- It involves iterative refinement of experimental design, experimental questions, or data obtained.

- It allows students to master specific research techniques.

- It helps students engage in reflection about the problems being investigated and the work being undertaken to address those problems.

- It requires communication of results, either through publication or presentations in various STEM venues.

- It is structured and guided by a mentor, with students assuming increasing ownership of some aspects of the project over time.

The committee confirmed the value of these experiences in improving the persistence of students from historically underrepresented groups in STEM fields and validating disciplinary identity. The importance of quality mentoring and the lack of sufficient professional development for faculty members were emphasized. For all dimensions of undergraduate research, including course-based research, the committee found that research on the efficacy of these experiences, relative to research on other interventions to advance undergraduate STEM education, was still in early stages of development. The report offered a research agenda with the potential to further advance the benefits of a range of approaches to undergraduate research to a broad and diverse group of students. With 60 years of NSF investment, undergraduate research has evolved from apprenticeship model-based opportunities for a limited number of individuals to include team-based and classroom-based opportunities for a diverse group of students. Applying the growing research base in undergraduate science, engineering, and mathematics education to the development of optimal research experiences for undergraduates is the next frontier. Within the NSF portfolio, there are a range of programs that provide the opportunity to explore these research questions as well as multiple approaches to engaging students in undergraduate research, including the Improving Undergraduate STEM Education (IUSE) program, the EHR (Education and Human Resources) Core Research (ECR) program, and the research track within the Advanced Technological Education (ATE) program.

For over 60 years, NSF has promoted and advanced undergraduate research, generally without adopting a scholarly stance and seeking to understand what students learn, who these experiences benefit, and how the experiences can be optimized to benefit all students. There is evidence of benefit, with as yet many unanswered questions. In looking to the future, a shift in mind-set to one of curiosity about students' learning is imperative. Integration of the growing and robust body of knowledge on how undergraduates learn can then be applied to the broad range of undergraduate research opportunities. For those investigating undergraduate learning, undergraduate research offers many opportunities to explore and contribute. As research on mentoring students grows, there are opportunities to provide professional development to research mentors, whether they are faculty, postdoctoral fellows, or graduate students. A deeper understanding of the benefits of different modalities of undergraduate research and practices that advance learning and inclusion can inform efforts to scale the benefits of undergraduate research to many more students. Even as students learn to be scholars, there is the opportunity to take a scholarly stance toward their research experiences.

\section{References}

Banta, Lois M., Erica J. Crespi, Ross H. Nehm, Jodi A. Schwarz, Susan Singer, Cathryn A. Manduca, Eliot C. Bush, et al. 2012. "Integrating Genomics Research throughout the Undergraduate Curriculum: A Collection of Inquiry-Based Genomics Lab Modules." CBE-Life Sciences Education 11: 203-202. doi: 10.1187/ cbe.11-12-0105

Campbell, A. Malcolm, Mary Lee S. Ledbetter, Laura L. M. Hoopes, Tod T. Eckdahl, Laurie J. Heyer, Anne Rosenwald, Edison Fowlks, Scott Tonidandel, Brooke Bucholtz, and Gail Gottfried. 2007. "Genome Consortium for Active Teaching: Meeting the Goals of BIO2010." CBE-Life Sciences Education 6: 109-118. doi: 10.1187/cbe.06-10-0196 
Carrier, Sam C., and David Davis-Van Atta. 1987. Maintaining America's Scientific Productivity: The Necessity of the Liberal Arts Colleges. Oberlin, OH: Oberlin College.

England, J. Merton 1982. A Patron for Pure Science: The National Science Foundation's Formative Years, 1945-57. Washington, DC: National Science Foundation (NSF 82-24). doi: $10.2307 / 1957721$

Jordan, Tuajuanda C., Sandra H. Burnett, Susan Carson, Steven M. Caruso, Kari Clase, Randall J. DeJong, John J. Dennehy, et al. 2014. "A Broadly Implementable Research Course for First-Year Undergraduate Students." mBio 5(1): e01051-13. doi: 10.1128/ mBio.01051-13

Laursen, Sandra, Anne-Barrie Hunter, Elaine Seymour, Heather Thiry, and Ginger Melton. 2010. Undergraduate Research in the Sciences: Engaging Students in Real Science. San Francisco: Jossey-Bass.

Leung, Wilson, Christopher D. Shaffer, Laura K. Reed, Sheryl T. Smith, William Barshop, William Dirkes, Matthew Dothager, et al. 2015. "Drosophila Muller F Elements Maintain a Distinct Set of Genomic Properties over 40 Million Years of Evolution." G3: Genes, Genomes, Genetics 5: 719-740. doi: 10.1534/ g3.114.015966

Maeroff, Gene I. 1985. "48 Colleges Seek Science Support." New York Times, June 16, 23.

National Academies of Sciences, Engineering, and Medicine (NASEM). 2017. Undergraduate Research Experiences for STEM Students: Successes, Challenges, and Opportunities. Washington, DC: National Academies Press. doi: 10.17226/24622

National Science and Technology Council, Committee on STEM Education. 2013. Federal Science, Technology, Engineering, and Mathematics (STEM) Education: 5-Year Strategic Plan. Washington, DC: Executive Office of the President. Accessed June 13, 2017. https://obamawhitehouse.archives.gov/sites/default/files/ microsites/ostp/stem_stratplan_2013.pdf

"National Science Foundation Grants for Undergraduate Research." 1958. Nature 182: 1346. doi: 10.1038/1821346c0

National Science Foundation (NSF). 1981. NSF FY 1982 Revised Budget 1981, J-4. Washington, DC: NSF.

National Science Foundation. 2019. NSF FY 2019 Budget Request. Washington, DC: NSF. Contains FY 2018 actuals, accessed October 27, 2019. https://www.nsf.gov/about/budget/ fy2019/index.jsp

National Science Foundation. 2020. NSF FY 2020 Budget Request. Washington, DC: NSF. Accessed October 27, 2019. https://www.nsf.gov/about/budget/fy2020/index.jsp.

President's Council of Advisors on Science and Technology (PCAST). 2012. Engage to Excel: Producing One Million Additional College Graduates with Degrees in Science, Technology, Engineering, and Mathematics. Washington, DC: Executive Office of the President. Accessed June 13, 2017. https://www.
energy.gov/sites/prod/files/Engage $\% 20$ to $\% 20$ Excel $\% 20$ Producing $\% 20$ One $\% 20$ Million $\% 20$ Additional $\% 20$ College $\% 20 \mathrm{Gradu}-$ ates $\% 20$ With $\% 20$ Degrees $\% 20$ in $\% 20$ STEM $\% 20$ Feburary $\% 20$ 2012.pdf

Rensselaer Polytechnic Institute (RPI). 2018-2019. Rensselaer Catalog. Accessed June 13, 2017. http://catalog.rpi.edu/content. php?catoid $=18 \&$ navoid $=437$

Ricketts, Palmer Chamberlain. 1934. History of Rensselaer Polytechnic Institute, 1824-1934, 3rd ed. New York: Wiley. Accessed December 13, 2019. http://digitool.rpi.edu:8881/R/94QX8MX4LYXCHEJ1 858EUEJ4HV9DINX573GGYABUBKY8UFPH63-00370?func=dbin-jump-full\&object_id=24989\&local_ base $=$ GEN01\&pds_handle $=$ GUEST

Staub, Nancy L., Marianne Poxleitner, Amanda Braley, Helen Smith-Flores, Christine M. Pribbenow, Leslie Jaworski, David Lopatto, and Kirk R. Anders. 2016. "Scaling Up: Adapting a Phage-Hunting Course to Increase Participation of First-Year Students in Research." CBE-Life Sciences Education 15(2): 1-11. doi: 10.1187/cbe.15-10-0211

Wei, Cynthia A., and Terry Woodin. 2011. "Undergraduate Research Experiences in Biology: Alternatives to the Apprenticeship Model." CBE-Life Sciences Education 10: 123-131. doi: $10.1187 /$ cbe.11-03-0028

Whitman, F. P. 1898. "The Beginnings of Laboratory Teaching in America." Science 8(190): 201-206. doi: 10.1126/ science.8.190.201

Zupanc, Günther K. H. 2012. "Undergraduate Research and Inquiry-Based Learning: The Revitalization of the Humboldtian Ideals." Bioscience Education 19: 1-11. doi: 10.11120/ beej.2012.19000011

\section{Susan Rundell Singer}

Rollins College, srsinger@rollins.edu

Susan Rundell Singer is a biologist, higher education researcher, and vice president for academic affairs and provost at Rollins College. She was division director for undergraduate education at the National Science Foundation and Gould Professor of Biology at Carleton College, where she directed the Perlman Center for Learning and Teaching. She pursues a career integrating science and education aimed at improving undergraduate education at scale. Singer is an American Association for the Advancement of Science (AAAS) Fellow and recipient of the American Society of Plant Biologists' Excellence in Education Award and the Botanical Society of America's Charles Edwin Bessey Teaching Award. She chaired the AAAS Education Section and serves on the National Academies of Science, Engineering, and Medicine's Board on Life Sciences and the Roundtable on Systemic Change in Undergraduate STEM Education. She chaired the National Academies' study Discipline-Based Education Research. 